\title{
An Overview of the Progress Made on the Coronavirus Vaccine
}

\author{
Yu Fang ${ }^{1, *}$ \\ ${ }^{1}$ The Episcopal school of Texas, San Antonio, Texas, USA
}

\begin{abstract}
The Coronavirus Disease-2019 (COVID-19) pandemic has led to a critical economic crash around the globe, affecting billions of people worldwide. Without a cure, the number of cases continues to increase exponentially. Countries, including the United States, Brazil, and India, currently lead in the number of cases with numbers soaring in the millions. Immunization is crucial to preventing the spread of infectious diseases and can help a large number of individuals quickly while keeping current cases under control. Following the publication of the genome sequence of SARS-CoV-2, vaccine development has been accelerated at an unprecedented rate. 115 vaccine candidates are currently under study with the hope of finding an ideal solution and mitigating the Coronavirus incidence rate. With some vaccine candidates having more potential than others, this review focuses on the characterization of different vaccine options. The analysis of probable vaccines, including mRNA vaccines and adenovirus vaccines, is conducted, and the scientific reasoning behind the vaccines is also discussed. In this review, the latest strategy vaccine is introduced and the effective vaccines are analysed.
\end{abstract}

\section{Introduction}

COVID-19, the cause of the 2020 worldwide pandemic, produces "asymptomatic to revere respiratory distress, pneumonia, and death [1]." The COVID-19 mortality rate is estimated to be $3.4 \%$ globally, and the elderly and pre-existing comorbidities are at a higher risk [2-4].

This global pandemic has brought up a world effort to develop a vaccine for COVID-19. The traditional vaccine development pipeline is usually taken upon 10 years, from conception to licensing. The classic approach to vaccine development may be hindered due to an abnormal degree of glycosylation in SARS-CoV-2, which leads to quick mutation. The glycosylation characteristics of SARS-CoV-2 allow it to "escape the detection of the human immune system and achieve the purpose of survival" due to its role in the replication and the host cell invasion of the virus.

Therefore, it is necessary to adopt new strategies to accelerate the development of vaccines, the subsequent preclinical and clinical trials, as well as the expansion of manufacturing, ensuring that the delivery of the potential candidate vaccines will not have any setbacks. Nowadays, the five technical routes of COVID-19 vaccine were adopted, see in Table 1.

Currently, the estimated vaccine for COVID-19 will be available widely in 18-24 months if clinical trials demonstrate safety, immunogenicity, and protective efficacy. In this review, the vaccine for COVID-19 will be systematically introduced.

\section{Introduction of SARS-CoV-2}

Since January 2020, SARS-CoV-2 has spread to more than 200 countries and has caused 4 million infections and over 250,000 deaths [5]. COVID-19 was declared a global pandemic by the WHO on 11th March 2020 [6]. The beta-coronavirus is the "causative agent" for two other viruses that produce "similar respiratory pathology." Due to the considerable homology with the SARS coronavirus in 2003, the International Committee for Classification of Viruses (ICTV) has established the term for RNA viruses that produce the pathology COVID-19 as SARS-CoV-2 [7]. The SARS-CoV-2 coronavirus, part of the Coronavirus subfamily, has a $(+)$ ss-RNA genomic structure of $30 \mathrm{~kb}$ in length, including a 5'-cap structure and a 3'-poly-A tail [8]. Polyprotein $1 \mathrm{a} / 1 \mathrm{ab}$ (ppla/pp1ab), from the viral RNA, is "synthesized in the host to form 16 non-structural proteins (nsps)," organizing "replication transcription complex (RTC) in double-membrane vesicles (DMV)." The nRTC discontinuously synthesizes a group of minus-strand subgenomic RNA (sgRNA) [9]. Within the open reading frames (ORFs), transcription is terminated, and successive acquisition of the leader RNA ensues [10]. In this process, the subgenomic mRNA requires sgRNAs as templates [11]. For a standard $\mathrm{CoV}$, including SARS-CoV-2, there are at least six ORFs.

The exact origin of the virus is yet to be discovered; however, genetic tracing has revealed that the virus shares homology with other strains of coronaviruses found in bats. Closely linked to two SARS-type coronaviruses occurring in bats, phylogenetic analysis

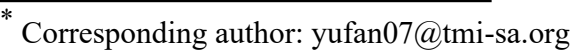


reveals that bat-SL-CoVZC45 and bat-SL- CoVZXC21 have $79 \%$ and $50 \%$ similarities with SARS-CoV and MER-CoV, respectively [12]. Particularly, the similarities in the RBD structure of SARS-CoV-2 and SARS-CoV demonstrate a divergence from a shared animal origin "within a short period [13-15]." However, since the sequence similarity between SARS-CoV-2 and its close relatives, bat-SL-CoVZC45 and bat-SLCoVZXC21, is less than $90 \%$, the virus found to be derived from bats may not be a direct source of SARSCoV-2. SARS-CoV-1, a viral outbreak in 2003, was possibly transmitted between bats and palm civets before human infection [16].

Middle Eastern Respiratory Syndrome (MERS)-CoV, the cause of a viral outbreak in Saudi Arabia in 2012, is another related coronavirus. The genomic evidence proposes that it circulated between bats and camels before it transmitted to humans, showing that bats are the natural reservoir species of coronavirus, and the zoonosis can occur between the human-to-animal interactions. Consequent outbreaks have determined a mortality rate of about $35 \%$, excluding the asymptomatic transmission [17-20].

\section{Introduction of Vaccines}

\subsection{Purpose of Vaccines}

Vaccines function by introducing viral antigens into the body, eliciting, and strengthening the immune response. After encountering the viral antigens from the vaccine, memory $\mathrm{T}$ and $\mathrm{B}$ cells will recognize viral invaders in the future, better preparing the immune system against illness. With vaccines, critical viral and bacterial infections may be eradicated by implementing herd immunity. When enough people are vaccinated, immune to the pathogen, entire populations benefit as the spread of the infectious disease slows down.

\subsection{Live Attenuated Vaccines}

Live attenuated vaccines (LAVS) utilize viruses that are unable to reproduce in cell cultures. Intact bacteria within an inactivated virus are killed by chemicals such as formaldehyde or by heat inactivation [21-23]. LAVS, displaying immunogenic characteristics, can "replicate the threshold of pregnancy and cellular immunosuppression caused by live viral infections [24]." As a result of requiring one or more additional doses, LAVS may not be a viable option for "more virulent viruses [25-26]" due to weaker immunogenicity and the "likelihood of reactivation in vaccinated individuals." From the point of view of vaccine distribution, LAVS are usually refrigerated to maintain immunogenicity, which can be difficult in countries that cannot maintain cold chain distribution [27].

\subsection{Protein Vaccines}

In order to produce an immunomodulatory response, protein vaccines are involved in the "protection of antigenic proteins." Created in vitro, the protein vaccine "manipulates the virus in the presence of pathogens [28]." This type of vaccine elicits a response to "humorous antipsychotics" with the plural administered with an adjuvant. This enhances the quality of immunosuppression while further "stimulating a... response." The virus-like particles hold a vaccine that contains many copies of the virus in "3D type structures," detecting "immunogenesis without involving adaptations [28]." Attractive for rapid vaccine development, subunit vaccines are increasingly popular with many organizations working on the development of protein subnet-based vaccines. They can be adapted to mass production at Good Manufacturing Practice (GMP) standards, and have less reliance on distributed cold chain systems $[25,29]$.

\subsection{Nucleic Acid Vaccines}

Nucleic acid vaccines utilize specific proteins from the "target pathogen" as immunogenic epitopes. Using plasmid DNA or RNA sequences as a vector, host cells produce pathogenic proteins with the body, eliciting an immune response. Vaccine delivery techniques include encapsulation of RNA in liposomes in order to avoid the degradation of "uncapsulated RNA vaccines" during the injection. In previous clinical trials relating to "cancer vaccines and functional antibodies against rabies virus glycoproteins," RNA vaccines revealed the ability to "induce specific responses to antigen antibodies and multifunctional T cells [30-31]." Nucleic acid vaccines have resulted in low immunogenicity in human clinical trials, requiring multiple doses and additional adjuvants. Only 4 DNA vaccines have been approved for use in animals; however, further study is needed on the efficacy of the vaccine in humans [31-32]. Nucleic acid vaccines are relatively cheap and easy to produce, and it is possible to produce GMP products on a large scale [33].

\subsection{The Recombinant Viral Vector Vaccine}

The recombinant viral vector vaccine generates selfassisted immunogenicity by employing the innate immunity of the host and "triggering a targeted immune response against genetically encoded pathogen antigens [34]." Previously discovered vaccines, such as the adenovirus, pox, and vesicular stomatitis virus, have viral vector "backbone(s)" constructed by transgenic viruses [35]. Containing "insertion sites for the target pathogen gene [36]," the vaccine may generate immunity towards the vector and "hinder the antigen-specific response upon a boost vaccination [35]." Furthermore, the viral vector, hAds, occurs at a "high frequency in most populations [37]," reducing vaccine efficacy due to "significant existing immunity [38]." ChAd, the chimpanzee adenovirus, remains a probable vector by "reducing seropositivity [39]" and "neutralizing 
antibodies [29]." Preclinical trials show "100\% efficacy [40]" and "good safety [35]." Clinical trials have determined that the ChAd vector also has good safety and immunogenicity against influenza A [41], Ebola virus [42], and Middle East respiratory syndrome [43].

\section{Approach and Mechanisms of SARS- CoV-2 Vaccines}

By exposing individuals to antigens, vaccination can produce lasting immunity, which drives the development of immune memory before encountering live pathogens. Vaccines provide "resulting immunity (that) can be mediated by humoral antibody induction and/or cellular T cell effector function [30-31]." Spike glycoprotein (S) is the only surface protein of SARS-CoV-2 virions [44]. SARS-CoV-2 S mediates viruses into host cells through angiotensin-converting enzyme 2 (ACE2), which is highly expressed on the surface of lung epithelial cells [45]. As for now, "the most clinically advanced COVID19 vaccines target the spike glycoprotein (S)." An important characteristic of the structure of SARS-CoV$2 \mathrm{~S}$ is that it shares homology with SARS-CoV-1[46-47]. In the SARS-CoV-2 infection, antibodies are generated against the $S$ protein and the internal nucleoprotein [48]. The "humoral protection arises through structural epitope recognition of proteins," so potential vaccines would generate "a long-lasting humoral immunity with protective titers of neutralizing antibodies that do not cause antibody-dependent enhancement (ADE) upon reinfection." ADE was detrimental in SARS-CoV-1 pathogenesis during the 2002-2003 outbreak [49], and preclinical trials demonstrated infection of macrophages via $\mathrm{ADE}$ [50], and lethal pneumonia in mice [51-52]. $\mathrm{ADE}$ is, therefore, of potential concern for a SARSCoV-2 vaccine.

Using the highly glycosylated homotrimeric $\mathrm{S}$ protein as an entry pathway, SARS-CoV-2 enters the host cell and fuses with the cell membrane through its structural changes. This process includes the binding of the $\mathrm{S} 1$ subunit to the host cell receptor, triggering trimer instability, and then separating the S1 subunit from the S2 subunit to form a highly stable fusion structure [1315]. To access the host cell receptor, the RBD in the $S 1$ subunit undergoes a hinge-like conformational change to hide or expose key receptor binding sites, which is very similar to SARS-CoV [13-15]. The high level of homology between the RBD structures indicates that the COVID-19 virus shares the same host cell receptor ACE2 as SARS-CoV [13-15]. Despite the similarities between the two, COVID-19 has unique distinctions, with the most significant change being "the RRAR amino acid sequence with the S1/S2 protease cleavage site," which is consistent with the characteristics of the furin recognition site. This general phenomenon occurs more frequently in influenza viruses than in SARS viruses with only one arginine [53]. Similarly, SARSCoV-2 and RaTG13 S proteins have 29 different amino acid residues, 17 of which are located at the RBD site. The RBD of SARS-CoV-2 is closer to the center of the trimeric $S$ protein, with one of the three RBDs in the $S$ protein spiraling upward to form a spatial conformation, thus aiding the binding of the virus to the host receptor ACE2, which shows that SARS-CoV-2 is more infectious than SARS [54].

The S protein helps viral entry of the target cell; however, this endocytosis relies on "the binding of the $\mathrm{S}$ protein to the membrane ACE2 receptor and the active activation of the $\mathrm{S}$ protein by cellular proteases [55]." Therefore, the vaccine against $\mathrm{S}$ protein provides a prevention method of the proliferation and spread of SARS-CoV-2. The vaccine may inhibit the initial activation of the $\mathrm{S}$ protein by blocking the binding of $\mathrm{S}$ protein to ACE2. SARS-CoV-2 infects cells independently of the transmembrane serine protease 2 (TMPRSS2) protein-coding gene, while cathepsins B and $\mathrm{L}$ directly activate the $\mathrm{S}$ protein in cells that do not express TMPRSS2, and SARS-CoV-2 fails to express it after infection TMPRSS2 cells. Analysis indicates that the use of TMPRSS2 inhibitors can significantly prevent SARS-CoV-2 from entering TMPRSS2, expressing cell lines while promoting TMPRSS2 expression can antagonize this inhibitory effect [56]. Therefore, if the antibody titer of the $\mathrm{S}$ protein is high enough to hinder the engulfing of the virus into the endosome or fusing on the surface of the host cell, then the virus infection related to the activation of the $\mathrm{S}$ protein and the release of the virus particles in the cell will be effectually suppressed [55].

Determining the ideal antibody titer requires thorough characterization of the stoichiometric relationship between the $\mathrm{S}$ protein and the immune response in order to avoid "redundant $S$ protein complexes that may effectively remove IgG antibodies to leave unblocked $\mathrm{S}$ protein available for processing and binding to ACE2." The "intrinsic ratio of $\mathrm{S}$ protein on the outer surface of each SARS-CoV- 2 virions (s/v) can predetermine the preference of induced $\mathrm{IgG}$ in immunological responses," and the ratio of nucleotides to the $\mathrm{S}$ protein may demonstrate "whether there are redundant $S$ proteins when IgG neutralizes the $S$ protein," minimizing the immunogenic effect of IgG. Ultimately, these two ratios will verify the amount of antibody titer needed and how much vaccine booster is required.

\section{The Progress of Various Vaccines}

\subsection{Adenovirus Vaccine}

The vaccine for COVID-19 is an essential tool for fighting the coronavirus. Nowadays, the five technical routes of COVID-19 vaccine were adopted (Table 1). 
Table1. Classification of COVID-19 vaccine technical route.

\begin{tabular}{ccccc}
\hline DNA & RNA & $\begin{array}{c}\text { Recombination } \\
\text { Protein }\end{array}$ & Inactivated & Virus vector \\
\hline Genexine( & Moderna & cdbio & sinovac & AstraZeneca \\
AnGes & BioNTech & Vaxine & Immunitor & Kentucky \\
Inovio & Arcturus & BioProcessing & Bharat Biotech & Gamaleya \\
Cadila(CADILAHC & CureVac(CVACO) & & & \\
NS) & & & \\
\hline
\end{tabular}

A derivative from other species, adenovirus (Ad) vectors deliver vaccine antigens against various infectious disease targets. Scientists use the adenovirus vaccine as a weaker version of COVID-19 that has the potential to alleviate the negative impact of COVID-19 on the body. The theory behind this idea is that the immune system recognizes engineered protein spikes; therefore, the antibodies combine to the spike and stop it from functioning. Therefore, scientists at Oxford University, in Biotechnology, China, and in Moderna, US, tend to use adenovirus vector to neutralize the antibodies against the coronavirus spike protein.

The SARS-CoV and MERS-CoV vaccines of various Ad vectors have been characterized in preclinical models, revealing body fluid and cell coronavirus reactions with anti-infective capabilities. Antibodies were determined by a modified cell pathogenic neutralization assay (NA) based on live SARS-CoV-2 and enzyme-linked immunosorbent assay (ELISA). The simian Ad vector expressing the MERS-CoV S protein is being evaluated in phase 1 clinical trial (NCT04170829). Researchers at Oxford University have initiated a phase $1 / 2$ study to explore the safety, immunogenicity, and efficacy of the SARS-CoV-2 vaccine using this platform (NCT04324606). The Beijing Institute of Biotechnology and CanSino Biologics Inc. (NCT04313127) are testing similar methods using human Ad5 serotypes (Table 2).

The Moderna research team has shown that the weakened version of the virus might only alleviate certain pathological symptoms, indicating that this type of vaccine is not strong. A weakened vaccine has a greater potential to apply to all people, including vulnerable groups like the elderly and infants. With the elderly, and at-risk population, experiencing the most severe symptoms associated with the virus, a weakened vaccine may be an effective and safe method of prevention.

\subsection{Ad5-nCoV Vaccine}

The biotechnology called $\mathrm{Ad} 5-\mathrm{nCoV}$ is undergoing Phase 2 trials. The Sinovac Biotech SARS-CoV-2 vaccine is made by the inactive part of the virus particle and adds alum as an immune enhancer. Sinovac has been used as the SARS vaccine that entered phase I clinical trials 16 years ago. The advantage of this vaccine is that it utilizes a traditional development method. The adenovirus type 5 is used to carry the coronavirus spike protein gene. Sinovac claims that its new vaccine candidate has a strong immune response and is produced in animal models; therefore, it is also highly safe [57].
The Ad5-nCoV (adenovirus) vaccine, focusing on neutralizing antibodies, has shown an efficient response in convalescent patients. The vaccine, developed at Oxford University, may be produced as the first vaccine under this environment, having already moved into Phase III. Biotech's vaccine in China has moved to Phase III as well; however, currently in China, COVID-19 is almost eradicated. In China, finding participants may be difficult as fewer potential trial patients may lead to more statistical errors, such as too small of a sample, possible confounding variables, etc. In contrast, the UK is experiencing significantly more cases more than China as they continue to battle the virus. As a result, the UK may get more chances to test the vaccine on large samples through local clinical trials. The researchers will have more ease finding eligible participants and more opportunities to study cases in their own area due to the continuous increase in cases.

\section{3 mRNA-1273 Vaccine}

The mRNA-1273 vaccine, developed by the National Institutes of Health (NIH) and a biotechnology company called Moderna, is different from the live-attenuated, inactivated or subunit vaccines at the focus in many other studies (Table 2). This mRNA vaccine utilizes the entry of human cells to produce the viral surface antigens, which are potentially protective against SARSCoV-2. The proposed mechanism contains these mRNA molecules within lipid nanoparticles in order to expedite the entry of this mRNA into a host cell. Once in the host cell, the antibody response will be achieved through the expression of the $\mathrm{S}$ protein. The mRNA vaccine is currently the most plausible solution due to its ability to be "scaled rapidly." These non-replicating mRNA vaccines can be separated into "ex vivo loading of dendritic cells and direct in vivo injection into various anatomical sites [58]." For exogenous mRNA to reach the cytoplasm prior to functional protein translation, the lipid membrane barrier must be penetrated. Uptake mechanisms of mRNA display cell specificity with the "physicochemical properties of the mRNA [59]" having the potential to affect "cellular delivery and organ distribution [60-61]."

Furthermore, difficulties surround clinical trials of the mRNA-1273 vaccine due to communication issues amongst researchers and novel security regulations established by the IACUC and DSMB regarding termination rules in relation to safety. A possibility remains with the IACUC deeming mRNA-1273 harmful, halting the analysis of preclinical results and the progress of phase I clinical trials. Preclinical safety results must 
be released prior to the progression of phase I trials; without this data, participants in human trials face unprecedented risks that are difficult to justify. New data monitoring and sharing techniques may aid "timely publication of results," ensuring that communication amongst researchers is standardized.

\subsection{ChAdOxI nCOV-19}

The adenovirus vaccine provides a weaker version of COVID-19 that has the potential to alleviate the negative impact of COVID-19 on the body. Current research reveals that a major mechanism in the neutralization of SARS-CoV includes the blockage of RBM found inside the RBD and the ACE2 association site [62]. This team found that a particular mAbs has immunogenic potential by binding to sites outside of the receptor-binding motif that may contribute to conformational change to the RBD in addition to neutralization without directly inhibiting ACE2 binding [56]. CR3022, a human neutralizing $\mathrm{mAb}$, showed "potent" binding in the study, recognizing the epitope outside of RBM. In addition, Shen pointed out that five severe COVID-19 patients with severe COVID-19 were given convalescent plasma after neutralizing the antibody, and their clinical condition improved [63]. These findings suggest that the use of convalescent plasma infusion may also be beneficial in COVID-19 patients. However, changes in the duration of immunity and the level of immunity of patients in the recovery phase still remain unknown. With increasing age, the neutralizing antibody titer increased significantly, which shows that plasma antibodies in middle-aged and elderly COVID-19 patients are significantly higher than the titer and peak binding antibody than in young patients [64-65]. This indicates that elderly patients may have stronger immune responses to SARS-CoV-2 than younger patients. In addition, the level of neutralizing antibodies in asymptomatic or mild patients was slightly lower than moderate or severe patients, which is consistent with other previous studies, which are concluded that severe cases are more common among patients with high IgG levels compared to those with low IgG levels [64,66-67]. The result of neutralizing antibodies depends on the onset of symptoms, age, and the severity of the disease.

At the University of Oxford, ChAdOxl nCOV-19 has recently entered clinical trials. ChAdOxl nCOV-19 utilizes viral vectored technology; the vaccine encodes SARS-CoV-2-S through a "replication-deficient" chimpanzee adenovirus vector to "encode SARS-CoV-2S [68-69]." With the objective of characterizing the vaccine itself and its safety, the analysis of preclinical and clinical trials has revealed that the vaccine is safe and induces humoral and cellular immunogenicity along with "durable protection [70-72]." At the beginning of the SARS-CoV-2 epidemic, the Jenner Institute collaborated with ChAdOx1-MERS-CoV at Oxford University to lead the development of a coronavirus vaccine against MERS-CoV through a phase I clinical trial. Kingdom of Saudi Arabia [73]. The first phase included 900 healthy volunteers aged 18-55 that were "vaccinated with 5x1010 viral particles (v.p). ChAdOx1 nCoV-19 or a Meningitis-ACWY vaccine via intramuscular vaccination, in a randomized $1: 1$ ratio of trial vaccine to control [74]." Further trials plan to increase sample size and age range with a plan to "recruit volunteers between the ages of 55-70, age 70+, and children age 5-12 years to assess the vaccine across broader demographics." The main purpose and common main purpose of this study are to evaluate the safety and effectiveness of the vaccine. The humoral and cellular immune response to the vaccine will be assessed as a secondary endpoint [75].

\subsection{Advantages and Disadvantages of mRNA Vaccines}

Compared with traditional methods, the use of mRNAbased antiviral vaccines has four major safety and efficacy advantages. First, mRNA-based antiviral vaccines can prevent "infection and insertion-induced mutagenesis due to the natural degradation of mRNA in the cell microenvironment [76]." Moreover, the modification of the engineered mRNA structure improves the effectiveness of the immunogen, thereby improving its stability and translation efficiency [77]. Next, a strong immune response may be elicited through the activation of CD8 + and CD4 $+\mathrm{T}$ cells through only one or two doses due to the high potency of mRNA vaccines [78]. Lastly, the treatment of large populations is viable due to the ability to mass-produce the vaccine $[9,79]$.

The Moderna vaccine focuses on mRNA molecules that express SARS-CoV-2-S. The proposed mechanism contains these mRNA molecules within lipid nanoparticles in order to expedite the entry of this mRNA into a host cell [80]. Once in the host cell, the antibody response will be achieved through the expression of the S protein. The analysis of "Phase I data for a pandemic influenza vaccine focused on a cohort vaccinated with $25 \mathrm{qg}$, $50 \mathrm{qg}$, or $100 \mathrm{gg}$ of the vaccine [81]." The Moderna vaccine has a "good safety profile;" $87 \%$ of volunteers receiving high doses in previous trials for "other pandemic diseases" like MERS and ZIKA demonstrated successful seroconversion, developing neutralizing antibodies. Despite this success, the previous trials failed to produce cell-mediated cytokine responses in volunteers [82]. Although the vaccine has worked for other maladies, a significant amount of research must be done before progressing the vaccine into human clinical trials. However, the platform did not produce any measurable response to cell-mediated cytokine [80]. Moderna has not yet introduced any viable mRNA- based vaccines to the market that may proceed to human clinical trials [83]. Based on the novel mRNA- based platform and the current use of animal models, many questions remain unanswered [84]. 
Table 2. The progress of COVID-19 vaccine.

\begin{tabular}{|c|c|c|c|c|c|c|}
\hline Organizer & name & $\begin{array}{l}\text { Technical } \\
\text { route }\end{array}$ & Clinical number & $\begin{array}{l}\text { Clinical } \\
\text { stage }\end{array}$ & $\begin{array}{l}\text { Starting } \\
\text { time }\end{array}$ & $\begin{array}{l}\text { Number of } \\
\text { people }\end{array}$ \\
\hline Moderna & mRNA-1273 & RNA & NCT0470427 & III & 2020727 & 30000 \\
\hline CNBG & 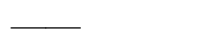 & Inactivated & Chi CTR200034780 & III & $2020 / 7 / 18$ & 15000 \\
\hline sinovac & & $\begin{array}{l}\text { Inactivated } \\
\text { vaccine }\end{array}$ & NCT04456595 & III & $2020 / 7 / 1$ & 8870 \\
\hline AstraZeneca & COV003 & Virus vector & ISRCTN89951424 & III & $2020 / 5 / 28$ & 2000 \\
\hline BioNTech & BNT162b28 & RNA & - & III & $2020 / 7 / 27$ & 30000 \\
\hline $\begin{array}{l}\text { cansinotech } \\
\text { Academy of }\end{array}$ & Ad5-nCov & Virus vector & ChicTR2000031781 & II & $2020 / 4 / 12$ & 500 \\
\hline $\begin{array}{l}\text { Military } \\
\text { Medical } \\
\text { Sciences }\end{array}$ & 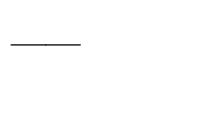 & recombination & NCT04341389 & II & $2020 / 4 / 12$ & 508 \\
\hline
\end{tabular}

\section{Discussion and Conclusion}

A safe, effective, and immunogenic vaccine must be developed to protect as many people as possible in order to decrease the influx of cases in hospitals. The lives of everyday people, in addition to healthcare workers, are at risk, and alleviating social distancing measures too soon may only further exacerbate the burden on health care systems around the world. The "regular circulation of SARS-CoV-2" is a major threat, and there are great gaps in information. With additional research and clinical trials, an effort towards a working vaccine may prove to be successful.

In order to produce a viable and immunogenic vaccine, there is more characterization needed for the antibody levels of patients with various severities of SARS-CoV-2. The Moderna research group suggests that studying the antibodies of recovered patients may answer an important concern when it comes to the development of a vaccine: how long do antibodies last at a safe level? Characterizing the retention time of the antibodies in a longitudinal sense and immunity duration is needed to confirm the safety of certain vaccines along with the identification of proper dosage. A major obstacle surrounding a viable vaccine is the unknown duration of immunity. For instance, dosage and booster requirements must be considered along with lifetime immunity possibilities. Whether "the vaccine will give lifelong immunity or longer duration of immunity with naturally acquired infection can be seen only much later" is another property that must be considered.

Even if a viable vaccine is created, the mass production and availability of the vaccine at an affordable price will be the next challenge. The nature of creating some vaccines may be more difficult than others. For example, in pathogens such as Malaria, the "sheer complexity of the parasite" hinders the development of its vaccine. The most effective Malaria vaccine requires the removal of the mosquito's salivary glands by hand, a very tedious process. This proves that although a solution may have been developed, the production and distribution become a key element in eradicating the disease. With regard to COVID -19, these obstacles must be considered in the progress and advancement of future vaccines.
Lastly, along with the manufacturing of the vaccine, choosing which patients will get the first shots will need to be decided. Ethics becomes an important part of making sure every patient has equal opportunity and access to the vaccine, a puzzle global public health authority still struggle to solve. Finances and social status often pose issues with furthering health disparities in at-risk populations across the world. Cultural differences also play a role in how willing a population is in receiving a vaccine. The HIV/AIDS epidemic revealed that implementing new health regulations and treatments can be more difficult than initially perceived. Denialism, fear of health authorities, and lack of access to resources all became critical when attempting to eradicate HIV/AIDS even when a vaccine was developed years after the first case. Whether a new COVID-19 vaccine could be equally distributed to all people in need regardless of their race, financial resources, and status remains unknown. To conclude, when developing a vaccine, diverse factors and complications must be examined. Despite the hardships and adversities, the effort to advance a viable and effective vaccine continues with researchers fighting to develop an ideal solution and stop the spread of SARSCoV-2.

\section{References}

1. Zhou M, Zhang X, Qu J. Coronavirus disease 2019 (COVID-19): a clinical update. Front Med. 2020.

2. worldometers.info. Coronavirus death rate 2020 [Available from: https://www.worldometers.info / co ronavirus/coronavirus-death-rate/),

3. Liu K, Chen Y, Lin R, Han K. Clinical features of COVID-19 in elderly patients: A comparison with young and middle-aged patients. J Infect. 2020.

4. F, Yu T, Du R, Fan G, Liu Y, Liu Z, et al. Clinical course and risk factors for mortality of adult inpatients with COVID-19 in Wuhan, China: a retrospective cohort study. Lancet. 2020;395(10229):1054-62.

5. worldometers.info. Countries where Coronavirus has spread 2020 [Available from: https://www.worldometers.info/coronavirus/countrie s-where-coronavirus-has-spread/. 
6. WHO.int.WHO Director-General's opening remarks at the media briefing on COVID-19-11 March 2020 [Available from: https://www.who.int/dg/speeches/detail/whodirector-general-s-opening-remarks-at-the-mediabriefing-on-covid-19---11-march-2020.

7. Coronaviridae Study Group of the International Committee on Taxonomy of Viruses. The species severe acute respiratory syndrome-related coronavirus: Classifying 2019-nCoV and naming it SARS-CoV-2. Nat Microbiol. 2020;5:536-44.

8. Liu Y, Gayle AA, Wilder-Smith A, Rocklov J. The reproductive number of COVID-19 is higher compared to SARS coronavirus. J Travel Med. 2020;27(2) pii: taaa021.

9. Zarghampoor F, Azarpira N, Khatami SR, et al. Improved translation efficiency of therapeutic mRNA. Gene. 2019;707:231-38.

10. Wang, F., Kream, R., \& Stefano, G. (2020, May 5). An Evidence Based Perspective on mRNA-SARSCoV-2 Vaccine Development. Retrieved July 09, 2020, from

https://www.ncbi.nlm.nih.gov/pmc/articles/PMC721 8962/

11. World Health Organization (WHO) Naming the coronavirus disease (COVID-19) and the virus that causes it. World Health Organization; https:/www.who.int/emergencies/diseases/novelcoronavirus-2019/technical-guidance/naming-thecoronavirus-disease-(covid-2019)-and-the-virusthat-causes-it.

12. Sun $P, \mathrm{Lu} X, \mathrm{Xu} C$, et al. Understanding of COVID19 based on current evidence. J Med Virol. 2020 [Epub ahead of print]

13. Zhang L, Lin D, Sun X, et al. Crystal structure of SARS-CoV-2 main protease provides a basis for design of improved a-ketoamide inhibitors. Science. 2020 [Epub ahead of print]

14. Yan R, Zhang Y, Li Y, et al. Structural basis for the recognition of the SARS-CoV-2 by full length human ACE2. Science. 2020;367(6485):1444-48.

15. Andersen KG, Rambaut A, Lipkin WI, et al. The proximal origin of SARS-CoV-2. Nat Med. 2020;26(4):450-52.

16. Lau SK, Woo PC, Li KS, Huang Y, Tsoi HW, Wong $\mathrm{BH}$, et al. Severe acute respiratory syndrome coronavirus-like virus in Chinese horseshoe bats. Proc Natl Acad Sci U S A. 2005;102(39):14040-5.

17. Azhar EI, El-Kafrawy SA, Farraj SA, Hassan AM, Al-Saeed MS, Hashem AM, et al. Evidence for camel- to-human transmission of MERS coronavirus. N Engl J Med. 2014;370(26):2499-505.

18. characterization of a newly discovered coronavirus associated with acute respiratory distress syndrome in humans. mBio. 2012;3(6).

19. Han HJ, Wen HL, Zhou CM, Chen FF, Luo LM, Liu $\mathrm{JW}$, et al. Bats as reservoirs of severe emerging infectious diseases. Virus Res. 2015;205:1-6.
20. Fung TS, Liu DX. Human Coronavirus: HostPathogen Interaction. Annu Rev Microbiol. 2019;73:529-57.

21. Thanh Le T, Andreadakis Z, Kumar A, Gomez Roman R, Tollefsen S, Saville $M$, et al. The COVID-19 vaccine development landscape. Nat Rev Drug Discov. 2020

22. Yamey G, Schaferhoff M, Hatchett R, Pate M, Zhao F, McDade KK. Ensuring global access to COVID19 vaccines. Lancet. 2020.

23. Lauring AS, Jones JO, Andino R. Rationalizing the development of live attenuated virus vaccines. Nat Biotechnol. 2010;28(6):573-9.

24. Pulendran B, Ahmed R. Immunological mechanisms of vaccination. Nat Immunol. 2011;12(6):509-17.

25. Lee J, Arun Kumar S, Jhan YY, Bishop CJ. Engineering DNA vaccines against infectious diseases. Acta Biomater. 2018;80:31-47.

26. Amanat F, Krammer F. SARS-CoV-2 Vaccines: Status Report. Immunity. 2020.

27. https://www.publichealth.org/publicawareness/understanding-vaccines/vaccines-work/.

28. Karch CP, Burkhard P. Vaccine technologies: From whole organisms to rationally designed protein assemblies. Biochem Pharmacol. 2016;120:1-14.

29. McClean S. Prospects for subunit vaccines: Technology advances resulting in efficacious antigens requires matching advances in early clinical trial investment. Hum Vaccin Immunother. 2016;12(12): 3103-6.

30. Geall AJ, Mandl CW, Ulmer JB. RNA: the new revolution in nucleic acid vaccines. Semin Immunol. 2013;25(2):152-9.

31. Ulmer JB, Mason PW, Geall A, Mandl CW. RNAbased vaccines. Vaccine. 2012;30(30):4414- 8.

32. Alberer M, Gnad-Vogt U, Hong HS, Mehr KT, Backert L, Finak G, et al. Safety and immunogenicity of a mRNA rabies vaccine in healthy adults: an open-label, non-randomised, prospective, first-in-human phase 1 clinical trial. Lancet. 2017;390(10101):1511-20.

33. Lee LYY, Izzard L, Hurt AC. A Review of DNA Vaccines Against Influenza. Front Immunol.2018;9:1568.

34. Vitelli A, Folgori A, Scarselli E, Colloca S, Capone S, Nicosia A. Chimpanzee adenoviral vectors as vaccines - challenges to move the technology into the fast lane. Expert Rev Vaccines. 2017;16(12): 1241-52.

35. Ewer KJ, Lambe T, Rollier CS, Spencer AJ, Hill AV, Dorrell L. Viral vectors as vaccine platforms: from immunogenicity to impact. Curr Opin Immunol. 2016;41:47-54.

36. Wu L, Zhang Z, Gao H, Li Y, Hou L, Yao H, et al. Open-label phase I clinical trial of Ad5- EBOV in Africans in China. Hum Vaccin Immunother. 2017;13(9):2078-85. 
37. Capone S, D'Alise AM, Ammendola V, Colloca S, Cortese R, Nicosia A, et al. Development of chimpanzee adenoviruses as vaccine vectors: challenges and successes emerging from clinical trials. Expert Rev Vaccines. 2013;12(4):379-93.

38. Henao-Restrepo AM, Camacho A, Longini IM, Watson CH, Edmunds WJ, Egger M, et al. Efficacy and effectiveness of an rVSV-vectored vaccine in preventing Ebola virus disease: final results from the Guinea ring vaccination, open-label, clusterrandomised trial (Ebola Qa Suffit!). Lancet. 2017;389(10068):505-18.

39. Lin JT, Zhang JS, Su N, Xu JG, Wang N, Chen JT, et al. Safety and immunogenicity from a phase I trial of inactivated severe acute respiratory syndrome coronavirus vaccine. Antivir Ther. 2007;12(7):110713.

40. Gao Q, Bao L, Mao H, Wang L, Xu K, Yang M, et al. Rapid development of an inactivated vaccine candidate for SARS-CoV-2. Science. 2020.

41. Antrobus RD, Coughlan L, Berthoud TK, Dicks MD, Hill AV, Lambe T, et al. Clinical assessment of a novel recombinant simian adenovirus $\mathrm{ChAdOx} 1$ as a vectored vaccine expressing conserved Influenza A antigens. Mol Ther. 2014;22(3):668-74.

42. Venkatraman N, Ndiaye BP, Bowyer G, Wade D, Sridhar S, Wright D, et al. Safety and immunogenicity of a heterologous prime-boost Ebola virus vaccine regimen - ChAd3-EBO-Z followed by MVA-EBO-Z in healthy adults in the UK and Senegal. J Infect Dis. 2018.

43. Folegatti PM, Bittaye M, Flaxman A, Lopez FR, Bellamy D, Kupke A, et al. Safety and immunogenicity of a candidate Middle East respiratory syndrome coronavirus viral-vectored vaccine: a dose-escalation, open-label, nonrandomised, uncontrolled, phase 1 trial. Lancet Infect Dis. 2020.

44. Wrapp D, Wang N, Corbett KS, Goldsmith JA, Hsieh CL, Abiona O, et al. Cryo-EM structure of the 2019-nCoV spike in the prefusion conformation. Science. 2020;367(6483):1260-3.

45. Letko M, Marzi A, Munster V. Functional assessment of cell entry and receptor usage for SARS-CoV-2 and other lineage B betacoronaviruses. Nat Microbiol. 2020;5(4):562-9.

46. Yang ZY, Kong WP, Huang Y, Roberts A, Murphy $\mathrm{BR}$, Subbarao K, et al. A DNA vaccine induces SARS coronavirus neutralization and protective immunity in mice. Nature. 2004;428(6982):561-4.

47. Wang YD, Sin WY, Xu GB, Yang HH, Wong TY, Pang $\mathrm{XW}$, et al. T-cell epitopes in severe acute respiratory syndrome (SARS) coronavirus spike protein elicit a specific T-cell immune response in patients who recover from SARS. J Virol. 2004;78(11):5612-8.

48. To KK, Tsang OT, Leung WS, Tam AR, Wu TC, Lung DC, et al. Temporal profiles of viral load in posterior oropharyngeal saliva samples and serum antibody responses during infection by SARS-CoV2: an observational cohort study. Lancet Infect Dis. 2020.

49. Tetro JA. Is COVID-19 receiving ADE from other coronaviruses? Microbes Infect. 2020;22(2):72-3.

50. Yip MS, Leung NH, Cheung CY, Li PH, Lee HH, Daeron M, et al. Antibody-dependent infection of hum

51. Channappanavar R, Fehr AR, Vijay R, Mack M, Zhao J, Meyerholz DK, et al. Dysregulated Type I Interferon and Inflammatory Monocyte-Macrophage Responses Cause Lethal Pneumonia in SARS-CoVInfected Mice. Cell Host Microbe. 2016;19(2):18193.

52. Bolles M, Deming D, Long K, Agnihothram S, Whitmore A, Ferris M, et al. A double- inactivated severe acute respiratory syndrome coronavirus vaccine provides incomplete protection in mice and induces increased eosinophilic proinflammatory pulmonary response upon challenge. J Virol. 2011 ;85(23): 12201-15.

53. Coutard B, Valle $C$, de Lamballerie $X$, et al. The spike glycoprotein of the new coronavirus 2019$\mathrm{nCoV}$ contains a furin-like cleavage site absent in $\mathrm{CoV}$ of the same clade. Antiviral Res. 2020;176:104742.

54. Kannan S, Shaik Syed Ali P, Sheeza A, Hemalatha K. COVID-19 (Novel Coronavirus 2019) - recent trends. Eur Rev Med Pharmacol Sci. 2020;24(4):2006-11.

55. Zhou J, Fang L, Yang Z, et al. Identification of novel proteolytically inactive mutations in coronavirus 3C-like protease using a combined approach. FASEB J. 2019;33(12):14575-87.

56. Hoffmann M, Kleine-Weber H, Schroeder S, et al. SARS-CoV-2 cell entry depends on ACE2 and TMPRSS2 and is blocked by a clinically proven protease inhibitor. Cell. 2020;181(2):271- 80.e8.

57. Jef Akst. COVID-19 vaccine frontrunners. The Scientist Magazine. (29 Apr 2020) Accessed 30 Apr 2020

58. Iavarone C, O'hagan DT, Yu D, et al. Mechanism of action of mRNA-based vaccines. Expert Rev Vaccines. 2017;16(9):871-81.

59. Schlake T, Thess A, Fotin-Mleczek M, Kallen KJ. Developing mRNA-vaccine technologies. RNA Biol. 2019;9(11):1319-30.

60. Midoux P, Pichon C. Lipid-based mRNA vaccine delivery systems. Expert Rev Vaccines. 2015;14(2): 221-34.

61. Kramps T, Elbers K. Introduction to RNA Vaccines. Methods Mol Biol. 2017;1499:1-11.

62. Liu QH, Zhu JK, Liu ZC, et al. Assessing the Global Tendency of COVID-19 Outbreak. medRxiv 2020; published online Mar 18.

63. Shen C, Wang Z, Zhao F, et al. Treatment of 5 Critically Ill Patients With COVID-19 With 
Convalescent Plasma. JAMA 2020; published online Mar 27.

64. Zhang L, Zhang F, Yu W, et al. Antibody Responses against SARS Coronavirus are Correlated with Disease Outcome of Infected Individuals. J Med Virol. 2006; 78:1-8.

65. Wu F, Wang AJ, Liu M, et al. Neutralizing Antibody Responses to SARS-CoV-2 in a COVID-19 Recovered Patient Cohort and their Implications. medRxiv 2020; published online Mar 30.

66. Zhao JJ, Yuan Q, Wang HY, et al. Antibody Responses to SARS-CoV-2 in Patients of Novel Coronavirus Disease 2019. medRxiv 2020; published online Mar 2.

67. Zhang BC, Zhou XY, Zhu CL, et al. Immune Phenotyping Based on Neutrophil-to-lymphocyte Ratio and IgG Predicts Disease Severity and Outcome for Patients with COVID-19. medRxiv 2020; published online Mar 12.

68. covid19vaccinetrial.co.uk. COVID-19 vaccine trial 2020 [Available from: https:// covid19vaccinetrial.co.uk.

69. Dicks MD, Spencer AJ, Edwards NJ, Wadell G, Bojang K, Gilbert SC, et al. A novel chimpanzee adenovirus vector with low human seroprevalence: improved systems for vector derivation and comparative immunogenicity. PLoS One. 2012;7(7):e40385.

70. van Doremalen N, Lambe $\mathrm{T}$, Sebastian $\mathrm{S}$, Bushmaker T, Fischer R, Feldmann F, et al. A single-dose ChAdOx1-vectored vaccine provides complete protection against Nipah Bangladesh and Malaysia in Syrian golden hamsters. PLoS Negl Trop Dis. 2019;13(6):e0007462.

71. Wilkie M, Satti I, Minhinnick A, Harris S, Riste M, Ramon RL, et al. A phase I trial evaluating the safety and immunogenicity of a candidate tuberculosis vaccination regimen, ChAdOx1 85A prime - MVA85A boost in healthy UK adults. Vaccine. 2020;38(4):779-89.

72. Coughlan L, Sridhar S, Payne R, Edmans M, Milicic A, Venkatraman $\mathrm{N}$, et al. Heterologous Two-Dose Vaccination with Simian Adenovirus and Poxvirus Vectors Elicits Long-Lasting Cellular Immunity to Influenza Virus A in Healthy Adults. EBioMedicine. 2018;29:146-54.

73. clinicaltrials.gov. A clinical trial to determine the safety and immunogenicity of healthy candidate MERS- CoV vaccine (MERS002) 2019 [Available from:https://clinicaltrials.gov/ct2/show/NCT041708 29.

74. clinicaltrials.gov. Safety and immunogenicity of a candidate MERS-CoV vaccine (MERS001) 2019 [Available from: https:/clinicaltrials.gov/ct2/show/NCT03399578.

75. clinicaltrials.gov. Study of a Candidate COVID-19 vaccine (COV001) 2020 [Available from: https://
clinicaltrials.gov/ct2/show/NCT04324606? cond $=$ co vid-19+vaccine $\&$ draw $=2 \&$ rank $=1$.

76. Lim B, Lee K. Stability of the osmoregulated promoter-derived proP mRNA is posttranscriptionally regulated by RNase III in Escherichia coli. J Bacteriol. 2015;197(7):1297- 305.

77. Pardi N, Weissman D. Nucleoside modified mRNA vaccines for infectious diseases. Methods Mol Biol. 2017;1499:109-21.

78. Knights AJ, Nuber N, Thomson CW, et al. Modified tumour antigen-encoding mRNA facilitates the analysis of naturally occurring and vaccine-induced CD4 and CD8 T cells in cancer patients. Cancer Immunol Immunother. 2009;58(3):325-38.

79. Ohto T, Konishi M, Tanaka H, et al. Inhibition of the inflammatory pathway enhances both the in vitro and in vivo transfection activity of exogenous in vitro-transcribed mRNAs delivered by lipid nanoparticles. Biol Pharm Bull. 2019;42(2):299-302.

80. Feldman RA, Fuhr R, Smolenov I, Mick Ribeiro A, Panther L, Watson M, et al. mRNA vaccines against H10N8 and H7N9 influenza viruses of pandemic potential are immunogenic and well tolerated in healthy adults in phase 1 randomized clinical trials. Vaccine. 2019;37(25):3326-34.

81. Pardi N, Hogan MJ, Pelc RS, Muramatsu H, Andersen H, DeMaso CR, et al. Zika virus protection by a single low-dose nucleoside-modified mRNA vaccination. Nature. 2017;543(7644):248-51.

82. WHO. DRAFT landscape of COVID-19 candidate vaccines 2020 [Available from: https://www.who.int /blueprint/priority-diseases/key-action/novelcoronavirus-landscape- ncov.pdf?ua $=1$.

83. Boodman, E. 2020. Researchers rush to test coronavirus vaccine in people without knowing how well it works in animals. STAT, https://www.statnews.com/2020/03/11/researchersrush-to-start-moderna-coronavirus-vaccine-trialwithout-usual-animal-testing/ (accessed April 3, 2020).

84. Nicole Lurie, MD, MSPH, Melanie Saville, M.D., Richard Hatchett, MD,et al;) Developing Covid-19 Vaccines at Pandemic Speed. The New England Journal of Medicine. (30 Mar 2020) . 